\title{
Diagnóstico do saneamento básico do município de Pindoretama-CE: proposta de prognóstico de água e esgoto
}

\author{
Diagnosis of the basic sanitation of the Pindoretama-CE \\ municipality: a proposed water and sewage prognosis
}
Diagnóstico do saneamiento básico en el municipio de Pindoretama- CE: propuesta de pronóstico de agua y desagüe

Maria Jorgiana Ferreira Dantas iD

jorgianaferreira@hotmail.com Faculdade de Ciências

Agronômicas - Unesp/FCA

Antônio Natanael Costa Sancho iD

natanael_ancs@hotmail.com Universidade Federal de Minas Gerais (UFMG)

José Jenvá Ferreira Júnior iD

Junior-ferreir@edu.unifor.br Universidade de Fortaleza Unifor

\section{Diagnostic de l'assainissement de base dans la municipalité de Pindoretama au l'état du Ceará, au Brésil: proposition de pronostic pour l'eau et les égouts}

\section{Resumo}

Com a promulgação da Lei Federal n. ${ }^{0} 11.445 / 2007$, os municípios foram obrigados a elaborar o planejamento da infraestrutura e ações de abastecimento de água, esgotamento sanitário, drenagem urbana e gestão de resíduos sólidos. O documento gerado dessa ferramenta é denominado de Plano Municipal de Saneamento Básico. Nesse contexto, encaixa-se o município de Pindoretama/CE, com população estimada de 22 mil habitantes. A metodologia consistiu na aquisição e tratamento de dados em órgãos oficiais e dados primários, com consulta à prestadora local dos serviços, o Serviço Autônomo de Água e Esgoto. Foi estimado um crescimento populacional do município com uma taxa 2,16\% e a previsão de custo para atender ao aumento da demanda baseou-se em tabelas oficiais do governo. $O$ diagnóstico indicou que $37,25 \%$ da população é abastecida por rede de distribuição de água, 50,14\% possuem abastecimento de água através de poços ou nascentes, e 12,61\% são abastecidos por outras formas de abastecimento. Quanto ao esgotamento sanitário, $99 \%$ dos efluentes são lançados em sistemas inadequados de tratamento e $36 \%$ da população não possui banheiro. O prognóstico indicou que será necessária a ampliação do sistema de abastecimento de água no município, com redução de perdas e instalação de estações de tratamento de água para as zonas urbanas. Quanto ao esgotamento, as zonas urbanas deverão implantar estações de tratamento de esgoto. Para a zona rural, deverão ser implantados sistemas individuais de abastecimento de água e fossas sépticas. $O$ custo estimado para as ações foi de $R \$ 95.6$ milhões ao longo dos 20 anos.

Palavras-chave: Saneamento básico. Gestão. Planejamento.

\begin{abstract}
According to the enactment of Federal Law No. 11.445/2007, municipalities were required to prepare infrastructure planning and actions for water supply, sanitary sewage, urban drainage, and solid waste management. This tool generated a document denominated Plano Municipal de Saneamento Básico. The municipality of Pindoretama fits in this context with an estimated population of 22 thousand inhabitants. The methodology consisted of the acquisition and treatment of data of official bodies and primary data in consultation with the local service provider, the Serviço Autônomo de Água e Esgoto. It was estimated population growth in the municipality with a $2.16 \%$ rate and the cost forecast to meet the increase in demand were based on official government tables. The diagnosis indicated that $37.25 \%$ of the population is supplied by the water distribution network, $50.14 \%$ have the water supply through wells or source and $12.61 \%$ are supplied by other forms of water supply. Regarding
\end{abstract}


sanitary sewage, $99 \%$ of effluents are released in inadequate treatment systems and $36 \%$ of the population does not have a toilet. The prognosis indicated that it will be necessary to expand the water supply system in the municipality, with a reduction of losses and installation of water treatment plants for urban areas. As for depletion, urban areas should establish sewage treatment plants. For the rural area, individual water supply systems and septic tanks should be implemented. The estimated cost for the actions will be R $\$ 95.6$ million over the 20 years.

Keywords: Basic sanitation. Management. Plan ning.

\section{Resumen}

Con la promulgación de la Ley Federal № 11.445/2007, los municipios fueron obligados a elaborar la planificación de la infraestructura y acciones de suministro de agua, desagüe sanitario, drenaje urbana y gestión de desechos sólidos. El documento generado de esta herramienta es el Plan Municipal de Saneamiento Básico. Se cuadra en este contexto el municipio de Pindoretama/CE con populación estimada de 22 mil habitantes. La metodología consistió en la adquisición y tratamiento de datos en instancias oficiales y datos primarios con consulta al proveedor local de servicios, el Servicio Autónomo de Agua y Desagüe. Se estimó un crecimiento de la población del municipio con una tasa 2,16\% y la previsión de coste para atender la subida de la demanda fue basada en tablas oficiales del gobierno. El diagnóstico indicó que $37,25 \%$ de la población es abastecida por red de reparto de agua, $50,14 \%$ poseen suministro de agua por pozos o nacientes y $12,61 \%$ son abastecidos por otras formas de suministro. Con relación al desagüe sanitario, $99 \%$ de los efluentes son lanzados en sistemas inapropiados de tratamiento y $36 \%$ de la población no posee aseo. El pronóstico indicó que se hará necesaria la ampliación del sistema de suministro de agua en el municipio, con reducción de pérdidas e instalación de estaciones de tratamiento de agua para las zonas urbanas. Con relación al desagüe, las zonas urbanas deberán implantar estaciones de tratamiento de desagüe. Para la zona del huerto, deberán ser implantados sistemas individuales de suministro de agua y fosas sépticas. El coste estimado para las acciones fue de $\mathrm{R} \$ 95.6$ millones a lo largo de los 20 años.

Palabras-clave: Saneamiento básico. Gestión. Planificación.

\section{Résumé}

Avec la promulgation de la loi fédérale $n^{\circ} 11.445 / 2007$, les municipalités doivent élaborer un plan de l'infrastructure et des actions pour l'approvisionnement d'eau, l'égout sanitaire, le drainage urbain et la gestion des déchets solides. Le document généré à partir de cette loi s'appelle le Plan d'Assainissement de base de la municipalité. La municipalité de Pindoretama / CE, avec une population estimée à 22000 habitants se trouve dans ce contexte. L'acquisition et le traitement de données dans des agences officielles, bien comme la consultation aux données primaires chez le fournisseur de services local, c'est à dire, le Service Autonome d'Eau et d'Égout (Serviço Autônomo de Água e Esgoto) a constitué la méthodologie d'étude. La croissance démographique de la municipalité était estimée à $2,16 \%$ et les coûts prévus pour répondre à cette demande ont été basés sur les tableaux officiels du gouvernement. Le diagnostic a révélé que $37,25 \%$ de la population est alimentée par un réseau de distribution d'eau, $50,14 \%$ par des puits ou par des sources d'eau et $12,61 \%$ par d'autres sources. En ce qui concerne l'égout sanitaire, $99 \%$ des effluents sont rejetés dans des systèmes de traitement inadéquats et $36 \%$ de la population ne dispose pas de toilettes. Le pronostic a indiqué qu'il sera nécessaire d'agrandir le système d'approvisionnement en eau à Pindoretama, en réduisant les pertes et en installant des stations de traitement de l'eau pour les zones urbaines. En ce qui concerne l'égout, les zones urbaines devront mettre en place des stations d'épuration des eaux usées. Pour les zones rurales, des systèmes individuels d'approvisionnement d'eau et des fosses septiques doivent être mises en place. Le coût estimatif de ces actions s'élève à 95,6 millions de Reais sur une période de 20 ans.

Mots-clés: Assainissement de base. Gestion. Planification. 


\section{Introdução}

Saneamento básico pode ser definido como os serviços e a infraestrutura necessária para o abastecimento de água, o esgotamento sanitário, a coleta e tratamento de resíduos sólidos e drenagem urbana, bem como operação, com a finalidade de preservar o meio ambiente e proteger a saúde da população (BRASIL, 2007), pois a existência desses equipamentos no meio urbano cessa a transmissão de doenças de veiculação hídrica e o despejo de esgoto bruto em corpos hídricos (JORDÃO e PESSÔA, 2014). Conforme dados do Sistema Nacional de Informações sobre Saneamento (SNIS), de responsabilidade da Secretaria Nacional de Saneamento Ambiental (SNSA), em 2016, 83,30\% da população brasileira tinha acesso ao abastecimento de água e $51,92 \%$ ao esgotamento sanitário (SNSA, 2018). Em 2015, os índices de abastecimento de água e esgotamento sanitário eram de $83,30 \%$ e $50,30 \%$, indicando crescimento nulo para o indicador de água e $1,62 \%$ para o esgoto (SNSA, 2017). No Nordeste, a realidade é bem distante da nacional. Somente $73,63 \%$ dos nordestinos possuem abastecimento de água e $26,79 \%$ são atendidos por redes de esgoto (BRASIL, 2011). A situação dos cearenses é ainda pior, com $64,06 \%$ da população abastecida com água tratada e somente $25,15 \%$ possuem coleta e tratamento dos efluentes domésticos (SNSA, 2018). Visando à universalização do saneamento básico, em janeiro de 2007, foi promulgada a Lei do Saneamento Básico, Lei n. ${ }^{\circ} 11.445 / 200$, o que tornou o planejamento do saneamento obrigatório para acesso aos recursos federais. O Decreto . $^{\circ} 7.217 / 2010$, que regulamenta a referida lei, estabelecia que o prazo para a elaboração dos Planos Municipais de Saneamento Básico (PMSB) seria até dezembro de 2014. Devido à dificuldade dos municípios em elaborar seus planos, o prazo tem sido constantemente prorrogado, estando o prazo final para 31 de dezembro de 2019, alterado através do Decreto $n .^{\circ} 9.254 / 2017$. O PMSB é de responsabilidade do município, que pode realizar por equipe própria ou por consultoria paga com recursos municipais ou por órgãos financiadores, como a Caixa Econômica Federal e a FUNASA - Fundação Nacional da Saúde (BRASIL, 2015). Conforme a Agência de Regulação do Ceará (Arce), dos 184 municípios cearenses, 59 finalizaram seus. Além disso, 71 estão em andamento e 54 não iniciaram ou não repassaram informações. Destes últimos, 31 PMSB's serão elaborados pela Associação dos Municípios do Estado do Ceará (Aprece), em vias de formalização. No tocante à Região Metropolitana de Fortaleza (RMF), os municípios que não possuem PMSB, ou não estão cobertos pela ação da Aprece, são Aracoiaba e Pindoretama (BRASIL, 2015). Tendo em vista a não existência do PMSB do município de Pindoretama/CE, este trabalho visa desenvolver um diagnóstico preliminar e propor um prognóstico operacional para o município, vindo a ser um referencial para a formulação de um produto.

\section{Metodologia}

A caracterização do município consistiu na pesquisa de dados secundários, em órgãos oficiais (Instituto Brasileiro de Geografia e Estatística - IBGE, Instituto de Pesquisa e Estratégia Econômica do Ceará - Ipece, Fundação Cearense de Meteorologia e Recursos Hídricos - Funceme) e a aquisição de dados primários na concessionária de água e esgoto, sites e livros que tenham correlações com a qualidade de vida da população e o saneamento, com a finalidade de analisar o impacto do saneamento na sociedade.

Quanto ao diagnóstico operacional, foram realizadas visitas ao município de Pindoretama e entrevista com o diretor do Sistema de Autônomo de Água e Esgoto (SAAE) do município. Também foram utilizados os dados do Sistema Nacional de Informações sobre Saneamento (SNIS) em conjunto com os dados do IBGE e Ipece, com a finalidade de verificar as atuais demandas do sistema e sua capacidade de atendimento. Projeção populacional: A estimativa de crescimento populacional foi realizada através do método geométrico (Eq.1), com a taxa de crescimento de 2,16\% ao ano por um período de 20 anos. Essa taxa representa o percentual de crescimento do município entre os censos de 1991 e 2010. Estimou-se, ainda, que a relação entre população urbana e população total do município aumenta $0,6 \%$ ao ano. A projeção ano a ano foi calculada em planilha Excel.

$$
P=P_{0}(1+i)^{t}
$$


Em que: P é a população no ano t (hab.); Po é a população de início de plano; i é a taxa de crescimento geométrico; t é o período.

Projeção de demanda: Para estimativa das demandas de água utilizou-se da per capita de 120 l/hab./ dia. Esse valor teve como referência a faixa de consumo per capita indicada para HELLER et al (2016) para cidades entre 10 mil a 50 mil habitantes. Esse valor foi multiplicado pela a população ano a ano, obtendo-se as vazões de trabalho do sistema, cuja equações são apresentadas abaixo. O período considerado foi de 20 anos (2019 - 2038). Vazão média de consumo (L/s): Eq. (2); Vazão máxima diária (L/s): Eq. (3); Vazão máxima horária (L/s): Eq. (4).

$$
\begin{aligned}
& Q_{\text {Méd }}=\frac{P \times q}{(1-i p) * 86400} \\
& Q_{\text {Diária }}^{Q_{\text {Má }}}=\frac{P \times q \times K_{1}}{(1-i p) * 86400} \\
& Q_{\text {Horária }}=\frac{P \times q \times K_{1} \times K_{2}}{(1-i p) * 86400}
\end{aligned}
$$

Em que: P é a população atendida (hab.); q é o consumo efetivo de água (L/hab./dia); ip é o índice de perdas definido; K1 é o coeficiente do dia de maior consumo; K2 é o coeficiente da hora de maior consumo.

Quanto à necessidade de reservação, adotou-se o valor de $1 / 3$ da demanda máxima diária (HELLER et al, 2016). O sistema de esgotamento sanitário é inexistente no município. Os habitantes utilizam fossas rudimentares ou despejam a céu aberto. Para o estudo de geração per capita de esgotos, foi considerado um coeficiente de retorno de 0,8 (TSUTIYA; SOBRINHO, 2011), o que resultou em um valor de $96 \mathrm{~L} / \mathrm{hab}$./dia para a zona urbana dos distritos e, para a zona rural, adotou-se que serão instaladas fossa sépticas para cada domicílio. Adotou-se uma taxa de infiltração na tubulação de 0,05 l/s./km de rede (TSUTIYA; SOBRINHO, 2011). A extensão da rede de esgoto foi estimada como sendo 8,1 m/ligação. Vazão média de esgoto (L/s): Eq. (5).

$$
\mathrm{Q}_{\text {Méd }}=\frac{\mathrm{P} \times \mathrm{q} \times 0,8}{86400}+S L
$$

Em que: $P$ é a população atendida (hab.); q é a per capita adotada (L/hab./dia); $S$ a infiltração; $L$ é a extensão da rede em quilômetros.

A quantidade de ligações foi estimada dividindo o número de habitantes atendidos pelo serviço dividido por 3,3 habitantes (IBGE, 2011). Previsão dos investimentos: Para a previsão de investimento foram utilizados os valores de base da Nota Técnica da Secretaria Nacional de Saneamento Ambiental n. ${ }^{\circ} 493 / 2010$, que disponibiliza indicadores de custos globais para obras de abastecimento de água e sistemas de esgotamento sanitário. Os valores apresentados nesse documento tiveram como base as obras do Programa de Aceleração do Crescimento, com tratamento estatisticamente diferenciado por categoria de região. Os valores apresentados foram atualizados pelo Índice Nacional da Construção Civil para março de 2018, multiplicando os valores pelo índice de 1,84, correspondente ao acumulado do INCC no período de 2008 a 2018. As tabelas 1 a 9 mostram os valores para cada tipo de sistema. Neste trabalho, foram adotados os valores de 10.000 a 20.000 domicílios

\begin{tabular}{|c|c|c|c|c|c|c|c|}
\hline \multirow{3}{*}{ INDICADOR } & \multirow{3}{*}{ ESPECIFICAÇÃO } & \multicolumn{5}{|c|}{ R\$/HABITANTE } & \multirow{3}{*}{$\begin{array}{c}\text { ATENDIMENTO } \\
\text { Demanda por } \\
\text { Intervençāo/SAA } \\
\text { Número de domicílios }\end{array}$} \\
\hline & & C Oeste & Nordeste & Norte & Sudeste & Sul & \\
\hline & & $3.1 \mathrm{hab} / \mathrm{dom}$ & $3.3 \mathrm{hab} / \mathrm{dom}$ & $3.5 \mathrm{hab} / \mathrm{dom}$ & $3.0 \mathrm{hab} / \mathrm{dom}$ & 2.9 hab/dom & \\
\hline \multirow{6}{*}{ IAA_C1 } & \multirow{6}{*}{$\begin{array}{l}\text { Gusto unitário de Captaçāo, por habitante } \\
\text { como ocupante domiciliar/familiar (PNAD- } \\
\text { IBGE, 2008); relacionado ao número de } \\
\text { famillias atendidas. Excluídos } \\
\text { Reservatórios de Regularizaçấ e } \\
\text { Barragens de qualquer porte. }\end{array}$} & 75,00 & 77,00 & 50,00 & 98,00 & 71,00 & $1.000<D<2.000$ \\
\hline & & 60,00 & 63,00 & 36,00 & 45,00 & RB & $2.001<\mathrm{D}<4.000$ \\
\hline & & 37,00 & 40,00 & 26.00 & 42,00 & 95,00 & $4.001<D<10.000$ \\
\hline & & 31,00 & 34,00 & 17,00 & 40,00 & RB & $10.001<\mathrm{D}<20.000$ \\
\hline & & 25,00 & 27,00 & 12,00 & 50,00 & $\mathrm{AB}$ & $20.001<D<34.000$ \\
\hline & & 19,00 & 22,00 & 11,00 & 50,00 & RB & $34.001<D<64.000$ \\
\hline
\end{tabular}
para a sede do município. Para os demais distritos e zona rural, foram utilizados os valores para cidades com domicílios entre 1.000 a 2.000 domicílios.

Tabela 1: Custo unitário de captação de água bruta por habitante.

Fonte: SNSA (2010). 
Diagnóstico do saneamento básico do município de Pindoretama-CE: proposta de prognóstico de água e esgoto

Tabela 2: Custo unitário de estação elevatória de água por habitante.

\begin{tabular}{|c|c|c|c|c|c|c|c|}
\hline \multirow{3}{*}{ INDICADOR } & \multirow{3}{*}{ ESPECIFICAÇÃO } & \multicolumn{5}{|c|}{ R\$/HABITANTE } & \multirow{3}{*}{$\begin{array}{c}\text { ATENDIMENTO } \\
\text { Demanda por } \\
\text { Intervençāo/SAA } \\
\text { Número de domicilios }\end{array}$} \\
\hline & & C Oeste & Nordeste & Norte & Sudeste & Sul & \\
\hline & & 3.1 hab/dom & $3.3 \mathrm{hab} / \mathrm{dom}$ & $3.5 \mathrm{hab} / \mathrm{dom}$ & $3.0 \mathrm{hab} / \mathrm{dom}$ & 2,9 hab/dom & \\
\hline \multirow{6}{*}{ IAA_C2 } & \multirow{6}{*}{$\begin{array}{l}\text { Custo unitário de Estaçāo Elevatória - } \\
\text { EE, por habitante como ocupante } \\
\text { domiciliar/familiar (PNAD-IBGE, 2008); } \\
\text { relacionado ao número de famílias } \\
\text { atendidas. }\end{array}$} & 110,00 & 45,00 & 63,00 & 50,00 & 108,00 & $1.000<\mathrm{D}<2.000$ \\
\hline & & 70,00 & 28,00 & 54,00 & 33,00 & RB & $2.001<\mathrm{D}<4.000$ \\
\hline & & 40,00 & 21,00 & 31,00 & 29,00 & RB & $4.001<\mathrm{D}<10.000$ \\
\hline & & 28,00 & 18,00 & 21,00 & 25,00 & RB & $10.001<D<20.000$ \\
\hline & & 19,00 & 14,00 & 15,00 & 13,00 & RB & $20.001<D<34.000$ \\
\hline & & 13,00 & 12,00 & 11,00 & 11,00 & $\mathrm{RB}$ & $34.001<\mathrm{D}<64.000$ \\
\hline
\end{tabular}

Fonte: SNSA (2010).

Tabela 3: Custo unitário de adutora de água por habitante.

\begin{tabular}{|c|c|c|c|c|c|c|c|}
\hline \multirow{3}{*}{ INDICADOR } & \multirow{3}{*}{ ESPECIFICAÇĀO } & \multicolumn{5}{|c|}{ R\$/HABITANTE } & \multirow{3}{*}{$\begin{array}{c}\text { ATENDIMENTO } \\
\text { Demanda por } \\
\text { Intervenção/SAA } \\
\text { Número de domicílios }\end{array}$} \\
\hline & & C Oeste & Nordeste & Norte & Sudeste & Sul & \\
\hline & & 3,1 hab/dom & $3,3 \mathrm{hab} / \mathrm{dom}$ & 3,5 hab/dom & 3,0 hab/dom & 2,9 hab/dom & \\
\hline \multirow{6}{*}{ IAA_C3 } & \multirow{6}{*}{$\begin{array}{l}\text { Custo unitário de Adução por habitante } \\
\text { como ocupante domiciliar/tamiliar (PNAD- } \\
\text { IBGE, 2008) relacionado ao número de } \\
\text { famillias atendidas.Considera: vazão } \\
\text { máxima diária; perda tísica de } 25 \% \text { e per } \\
\text { capita de consumo de } 125 \mathrm{l} / \mathrm{dia} \text { (SNIS/2007) }\end{array}$} & 156,00 & 170,00 & 71,00 & 145,00 & RB & $1.000<D<2.000$ \\
\hline & & 116,00 & 34,00 & 59,00 & 32,00 & RB & $2.001<\mathrm{D}<4.000$ \\
\hline & & 80,00 & 37,00 & 49,00 & 48,00 & $\mathrm{RB}$ & $4.001<\mathrm{D}<10.000$ \\
\hline & & 54,00 & 30,00 & 38,00 & 58.00 & $\mathrm{RB}$ & $10.001<\mathrm{D}<20.000$ \\
\hline & & 40,00 & 45,00 & 33,00 & 75,00 & RB & $20.001<\mathrm{D}<34.000$ \\
\hline & & 34,00 & 59,00 & 27,00 & 100,00 & $\mathrm{RB}$ & $34.001<\mathrm{D}<64.000$ \\
\hline
\end{tabular}

Fonte: SNSA (2010).

Tabela 4: Custo unitário de estação de tratamento de água por habitante.

\begin{tabular}{|c|c|c|c|c|c|c|c|}
\hline \multirow{3}{*}{ INDICADOR } & \multirow{3}{*}{ ESPECIFICAÇĀO } & \multicolumn{5}{|c|}{$\mathrm{R} \$ / \mathrm{HABITANTE}$} & \multirow{3}{*}{$\begin{array}{c}\text { ATENDIMENTO } \\
\text { Demanda por } \\
\text { Intervenção/SAA } \\
\text { Número de domicílios }\end{array}$} \\
\hline & & C Oeste & Nordeste & Norte & Sudeste & Sul & \\
\hline & & 3,1 hab/dom & 3,3 hab/dom & $3,5 \mathrm{hab} / \mathrm{dom}$ & 3,0 hab/dom & 2,9 hab/dom & \\
\hline \multirow{6}{*}{ IAA_C5 } & \multirow{6}{*}{$\begin{array}{l}\text { Custo unitário de Tratamento ETA por } \\
\text { habitante obtido como ocupante familiar } \\
\text { (IBGE, 2008) relacionado ao número de } \\
\text { tamilias atendidas. Cotejo com Manuais } \\
\text { Técnicos }\end{array}$} & 320,00 & 101,00 & 50,00 & 110,00 & RB & $1.000<\mathrm{D}<2.000$ \\
\hline & & 210,00 & 90,00 & 50,00 & 70,00 & RB & $2.001<\mathrm{D}<4.000$ \\
\hline & & 85,00 & 70,00 & 63,00 & 70,00 & RB & $4.001<\mathrm{D}<10.000$ \\
\hline & & 75,00 & 70,00 & 63,00 & 70,00 & RB & $10.001<\mathrm{D}<20.000$ \\
\hline & & 67,00 & 70,00 & 63,00 & 70,00 & 52,00 & $20.001<\mathrm{D}<34.000$ \\
\hline & & 60,00 & 60,00 & 63,00 & 70,00 & RB & $34.001<\mathrm{D}<64.000$ \\
\hline
\end{tabular}

Fonte: SNSA (2010).

Tabela 5: Custo unitário de sistema de reservação de água por habitante.

\begin{tabular}{|c|c|c|c|c|c|c|c|}
\hline \multirow{3}{*}{ INDICADOR } & \multirow{3}{*}{ ESPECIFICAÇÃO } & \multicolumn{5}{|c|}{$\mathrm{R} \$ / \mathrm{HABITANTE}$} & \multirow{3}{*}{$\begin{array}{c}\text { ATENDIMENTO } \\
\text { Demanda por } \\
\text { Intervençāo/SAA } \\
\text { Número de domicílios }\end{array}$} \\
\hline & & C Oeste & Nordeste & Norte & Sudeste & Sul & \\
\hline & & 3.1 hab/dom & 3.3 hab/dom & 3.5 hab/dom & 3.0 hab/dom & 2.9 hab/dom & \\
\hline \multirow{6}{*}{ IAA_C6 } & \multirow{6}{*}{$\begin{array}{l}\text { Custo unitário de Reservaçāo por } \\
\text { habitante como ocupante domiciliar } \\
\text { (IBGE, 2008) relacionado ao número de } \\
\text { familias atendidas. }\end{array}$} & 52,00 & 55,00 & 46,00 & 174,00 & RB & $1.000<\mathrm{D}<2.000$ \\
\hline & & 48,00 & 50,00 & 43,00 & 111,00 & RB & $2.001<\mathrm{D}<4.000$ \\
\hline & & 45,00 & 47,00 & 41,00 & 44,00 & RB & $4.001<\mathrm{D}<10.000$ \\
\hline & & 29,00 & 40,00 & 34,00 & 25,00 & $\mathrm{RB}$ & $10.001<\mathrm{D}<20.000$ \\
\hline & & 26,00 & 30,00 & 26,00 & 15,00 & RB & $20.001<\mathrm{D}<34.000$ \\
\hline & & 24,00 & 24,00 & 23,00 & 12,00 & RB & $34.001<\mathrm{D}<64.000$ \\
\hline
\end{tabular}

Fonte: SNSA (2010). 
Tabela 6: Custo unitário de rede de distribuição de água por habitante.

\begin{tabular}{|c|c|c|c|c|c|c|c|}
\hline \multirow{3}{*}{ INDICADOR } & \multirow{3}{*}{ ESPECIFICAÇÄO } & \multicolumn{5}{|c|}{ R\$/HABITANTE } & \multirow{3}{*}{$\begin{array}{c}\text { ATENDIMENTO } \\
\text { Demanda por } \\
\text { Intervençấ/SAA } \\
\text { Número de domicílios }\end{array}$} \\
\hline & & C Oeste & Nordeste & Norte & Sudeste & Sul & \\
\hline & & 3,1 hab/dom & 3,3 hab/dom & 3,5 hab/dom & 3,0 hab/dom & 2,9 hab/dom & \\
\hline \multirow{6}{*}{ IAA_C7 } & \multirow{6}{*}{$\begin{array}{l}\text { Custo unitário de Rede de } \\
\text { Distribuiçâo por habitante relacionado } \\
\text { ao número de famílias atendidas. } \\
\text { Considera vazão máxima horária; } \\
\text { perda física de } 25 \% \text { e per capita de } \\
\text { consumo de } 125 \mathrm{~V} / \mathrm{dia} \text { a } 150 \mathrm{~V} / \mathrm{dia} \text {. }\end{array}$} & 245,00 & 294,00 & 199,00 & 260,00 & RB & $1.000<D<2.000$ \\
\hline & & 200,00 & 194,00 & 123,00 & 182,00 & RB & $2.001<\mathrm{D}<4.000$ \\
\hline & & 70,00 & 67,00 & 86,00 & 73,00 & RB & $4.001<D<10.000$ \\
\hline & & 37,00 & 30,00 & 49,00 & 39,00 & 33,00 & $10.001<D<20.000$ \\
\hline & & 23,00 & 16,00 & 11,00 & 17,00 & RB & $20.001<D<34.000$ \\
\hline & & 13,00 & 8,00 & 9,00 & 17,00 & RB & $34.001<\mathrm{D}<64.000$ \\
\hline
\end{tabular}

Fonte: SNSA (2010).

Tabela 7: Custo unitário de ligação de água por residência.

\begin{tabular}{|c|c|c|c|c|c|c|c|}
\hline \multirow{3}{*}{ INDICADOR } & \multirow{3}{*}{ ESPECIFICAÇÄO } & \multicolumn{5}{|c|}{ R\$/HABITANTE } & \multirow{3}{*}{$\begin{array}{c}\text { ATENDIMENTO } \\
\text { Demanda por } \\
\text { Intervençāo/SAA } \\
\text { Número de domicílios }\end{array}$} \\
\hline & & C Oeste & Nordeste & Norte & Sudeste & Sul & \\
\hline & & 3,1 hab/dom & $3,3 \mathrm{hab} / \mathrm{dom}$ & 3,5 hab/dom & $3,0 \mathrm{hab} / \mathrm{dom}$ & 2,9 hab/dom & \\
\hline IAA_C9 & $\begin{array}{l}\text { Custo médio unitário de Ligação } \\
\text { domiciliar por habitante relacionado } \\
\text { ao número de famílias atendidas }\end{array}$ & 35,00 & 67,00 & 64,00 & 83,00 & 36,00 & $D<64.000$ \\
\hline
\end{tabular}

Fonte: SNSA (2010).

Tabela 8: Custo global para instalação de sistema de abastecimento de água por habitante.

\begin{tabular}{|c|c|c|c|c|c|c|c|c|}
\hline \multirow{3}{*}{ INDICADOR } & \multirow{3}{*}{ ESPECIFICAÇÃO } & \multicolumn{6}{|c|}{ R\$/HABITANTE } & \multirow{3}{*}{$\begin{array}{c}\text { ATENDIMENTO } \\
\text { Demanda por } \\
\text { Intervençăo/SAA } \\
\text { Número de domicílios }\end{array}$} \\
\hline & & C Oeste & Nordeste & Norte & Sudeste & Sul & BRASIL & \\
\hline & & 3,1 hab/dom & $3,3 \mathrm{hab} / \mathrm{dom}$ & 3,5 hab/dom & 3,0 hab/dom & 2,9 hab/dom & 3,1 hab/dom & \\
\hline \multirow{6}{*}{ IAA_CG } & \multirow{6}{*}{$\begin{array}{l}\text { Composição do Custo } \\
\text { Global de Sistema de } \\
\text { Abastecimento de Agua por } \\
\text { habitante como ocupante } \\
\text { domiciliar (IBGE; 2008) }\end{array}$} & 993,00 & 809,00 & 543,00 & 920,00 & 1.196 .00 & 904 & $1.000<D<2.000$ \\
\hline & & 739,00 & 526,00 & 429,00 & 556,00 & 723,00 & 575 & $2.001<D<4.000$ \\
\hline & & 392,00 & 349,00 & 360,00 & 389,00 & 511,00 & 393 & $4.001<\mathrm{D}<10.000$ \\
\hline & & 289.00 & 289,00 & 286.00 & 340,00 & 442,00 & 333 & $10.001<\mathrm{D}<20.000$ \\
\hline & & 235,00 & 269,00 & 224,00 & 323,00 & 366,00 & 300 & $20.001<D<34.000$ \\
\hline & & 198,00 & 252,00 & 208,00 & 343,00 & 437,00 & 307 & $34.001<D<64.000$ \\
\hline IAA_CGm & Custo Global Médio & 474,00 & 416,00 & 342,00 & 479,00 & 612,00 & 469,00 & - \\
\hline
\end{tabular}

Fonte: SNSA (2010).

Tabela 9: Custo global para instalação de sistema de esgotamento sanitário por habitante.

\begin{tabular}{|c|c|c|c|c|c|c|c|c|}
\hline \multirow{3}{*}{ INDICADOR } & \multirow{3}{*}{ ESPECIFICAÇÃO } & \multicolumn{6}{|c|}{$\mathrm{R} \$ / \mathrm{HABITANTE}$} & \multirow{3}{*}{$\begin{array}{c}\text { ATENDIMENTO } \\
\text { Demanda por } \\
\text { Intervençăa/SES } \\
\text { Número de domicílios }\end{array}$} \\
\hline & & C Oeste & Nordeste & Norte & Sudeste & Sul & BRASIL & \\
\hline & & 3,1 hab/dom & 3,3 hab/dom & 3,5 hab/dom & 3,0 hab/dom & 2,9 hab/dom & 3,1 hab/dom & \\
\hline \multirow{11}{*}{ IES_CG } & \multirow{11}{*}{$\begin{array}{l}\text { Composição do Custo } \\
\text { Global de Sistema de } \\
\text { Esgotamento Sanitário por } \\
\text { habitante como ocupante } \\
\text { domiciliar (IBGE; 2008) }\end{array}$} & 1695,00 & 1970,00 & 743,00 & 2181,00 & 1433,00 & 1605,00 & $1.001<D<2.000$ \\
\hline & & 1368,00 & 1052,00 & 499,00 & 1140,00 & 870,00 & 986,00 & $2.001<\mathrm{D}<4.000$ \\
\hline & & 915,00 & 928,00 & 489,00 & 586,00 & 876,00 & 759,00 & $4.001<\mathrm{D}<6.000$ \\
\hline & & 814,00 & 897,00 & 468,00 & 583,00 & 895,00 & 731,00 & $6.001<D<10.000$ \\
\hline & & 711,00 & 855,00 & 461,00 & 585,00 & 908,00 & 704,00 & $10.001<D<12.000$ \\
\hline & & 646,00 & 821,00 & 454,00 & 585,00 & 913,00 & 684,00 & $12.001<\mathrm{D}<14.000$ \\
\hline & & 580,00 & 808,00 & 442,00 & 585,00 & 918,00 & 667,00 & $14.001<\mathrm{D}<16.000$ \\
\hline & & 513,00 & 789,00 & 434,00 & 585,00 & 924,00 & 649,00 & $16.001<\mathrm{D}<18.000$ \\
\hline & & 476,00 & 763,00 & 426,00 & 588,00 & 941,00 & 639,00 & $18.001<D<20.000$ \\
\hline & & 417,00 & 612,00 & 371,00 & 585,00 & 990,00 & 595,00 & $20.001<D<34.000$ \\
\hline & & 327,00 & 539,00 & 335,00 & 586,00 & 981,00 & 554,00 & $34.001<\mathrm{D}<64.000$ \\
\hline IES_CGm & Custo Global Médio & 769,00 & 912,00 & 466,00 & 781,00 & 968,00 & 779,00 & - \\
\hline
\end{tabular}

Fonte: SNSA (2010). 
Como valor de referência para as cisternas, adotou-se R $\$ 6.419,54$ (SANTOS FILHO, 2014) e os banheiros foram estimados pelo modelo padrão da Funasa, utilizando a tabela 24.1 da Secretaria de Infraestrutura do Estado do Ceará, com BDI de $30 \%$. A Tabela 10 apresenta os valores adotados neste trabalho.

Tabela 10: Valores unitários adotados para a previsão de investimento em saneamento para o município de Pindoretama.

\begin{tabular}{c|l|rr|l|l}
\hline Item & \multicolumn{1}{|c|}{ Serviço } & \multicolumn{2}{c|}{ Valor unitário } & \multicolumn{1}{c}{ Unidade } & \multicolumn{1}{c}{ Fonte } \\
\hline 1 & Captação & RS & 62,56 & hab. & SNSA(2010) \\
\hline 2 & Elevatória de água & RS & 33,12 & hab. & SNSA (2010) \\
\hline 3 & Adutora de água & RS & 55,20 & hab. & SNSA (2010) \\
\hline 4 & Estação de Tratamento de água & RS & 128,80 & hab. & SNSA(2010) \\
\hline 5 & Reservatório & RS & 73,60 & hab. & SNSA (2010) \\
\hline 6 & Rede de água & RS & 55,20 & hab. & SNSA (2010) \\
\hline 7 & Ligacão domiciliar & RS & 123,28 & hab. & SNSA (2010) \\
\hline 8 & Instalação Sistema de Abastecimento de Água & RS & $1.488,56$ & hab. & SNSA (2010) \\
\hline 9 & Implantação de Sistema de Esgotamento Sanitário & RS & $1.678,08$ & hab. & SNSA(2010) \\
\hline 10 & Instalação de Fossa Séptica & RS & $3.323,80$ & Unidade & SEINFRACE \\
\hline 11 & Cisterna & RS & $6.419,54$ & Unidade & FILHO (2014) \\
\hline 12 & Banheiro & RS & $13.116,22$ & Unidade & Composição/SEINFRA \\
\hline
\end{tabular}

\section{Resultados e discussão}

Conforme dados do censo 2010, o município de Pindoretama apresentava 1.989 domicílios ligados à rede de abastecimento de água, o que representava 37,24 \% em relação ao total do município. Apesar de praticamente ter dobrado o número de residências ligadas à rede de água, observa-se que grande parte da população ainda era abastecida por poços ou nascentes, categoria que também inclui chafarizes (IBGE, 2011), como apresentado na Tabela 11. Conforme dados do Sistema Nacional de Informações Sobre Saneamento (SNIS), em 2016, a população atendida pela rede de água era de 12.335 habitantes, representando, aproximadamente, $60 \%$ da população total do município. Esse número é relativo à população urbana do distrito sede. Os demais munícipes utilizam de sistemas alternativos de abastecimento de água.

Tabela 11: Domicílios permanentes por tipo de abastecimento de água.

\begin{tabular}{l|r|r|r|r|c|c|c|c}
\hline \multirow{2}{*}{ Formas de abastecimentos } & \multicolumn{4}{|c|}{ Municipio } & \multicolumn{4}{c}{ Estado } \\
\cline { 2 - 10 } & \multicolumn{1}{|c|}{2000} & $\%$ & 2010 & $\%$ & 2000 & $\%$ & 2010 & $\%$ \\
\hline Total & 3.503 & 100,00 & 5.341 & 100,00 & 1.757 .888 & 100,00 & 2.365 .276 & 100,00 \\
Ligada a rede geral & 993 & 28,35 & 1.989 & 37,24 & 1.068 .746 & 60,80 & 1.826 .543 & 77,22 \\
Poço ou nascente & 2.212 & 63,15 & 2.677 & 50,12 & 360.737 & 20,52 & 221.161 & 9,35 \\
Outra & 298 & 8,51 & 675 & 12,64 & 328.405 & 18,68 & 317.565 & 13,43 \\
\hline
\end{tabular}

Fonte: Ipece (2018).

Quanto ao Sistema de Abastecimento de Água, este apresentava 3.491 ligações das quais 2.637 eram ativas, tendo extensão de rede de $30 \mathrm{Km}$ (SNIS, 2018). Em relação à micromedição, $0,62 \%$ das economias possuem hidrômetros. Conforme SNIS (2018), a rede distribuição de água apresenta grande percentual de perdas, com 41,48\% na distribuição, resultando em 16,62 metros cúbicos de água perdidos por dia a cada quilômetro de tubulação. Esse valor é elevado, devendo o município estabelecer procedimentos para a diminuição do indicador, tais como: equipes para retirada de vazamentos e identificação de ligações irregulares na rede. Em 2016, 438,6 mil metros cúbicos de água foram produzidos pela ETA do município, mas somente 256,6 mil 
metros cúbicos chegaram às residências da população, pois boa parte da água foi perdida para limpeza de filtros e por vazamentos. Quanto ao faturamento, 365 mil metros cúbicos de água foram faturados para o SAAE, indicando que mais de 900 economias consumiram acima de $10 \mathrm{~m}^{3}$ por mês (volume mínimo) (SNIS, 2018). ATabela 12 apresenta um resumo das informações operacionais de água do município e seus indicadores.

Tabela 12: População e domicílios atendidos pelo SAAE do município de Pindoretama/CE.

\begin{tabular}{l|l}
\hline \multicolumn{2}{l}{ INFORMAÇÕES OPERACIONAIS } \\
\hline População Atendida (hab.) & 12.335 \\
\hline Total de Ligações & 3.491 \\
\hline Ligações Ativas & 2.637 \\
\hline Ligações Ativas Micromedidas & 2.351 \\
\hline Economias Residenciais & 2.464 \\
\hline Residências Micromedidas & 2.188 \\
\hline Volume Produzido (2016) & 438.600 \\
\hline Volume Micromedido & 226.940 \\
\hline Volume Consumido & 256.660 \\
\hline Volume Faturado & 365.460 \\
\hline Extensão da Rede (km) & 30 \\
\hline
\end{tabular}

Fonte: SNIS (2016).

Os dados revelam que a população urbana vive com menos de $60 \mathrm{l} / \mathrm{habitante/dia,} \mathrm{valor} \mathrm{menor} \mathrm{que} \mathrm{o}$ recomendado pela ONU, que é de $110 \mathrm{I} /$ habitante/dia, resultado das perdas e do desabastecimento do sistema causado por problemas na adutora. Verifica-se que $100 \%$ da água ofertada para a população é fluoretada, auxiliando na prevenção de cáries, e que o consumo com energia do sistema é de 0,68 Kwh/m³ de água. Em relação ao esgotamento sanitário do município, não há rede de esgotamento sanitário. A população utiliza fossas negras ou despejo direto no solo. Poucos possuem fossas sépticas, que é a mais indicada para quando não existe sistema de coleta e tratamento no município. A Tabela 13 apresenta informações coletadas no último censo do IBGE

Tabela 13: Domicílios permanentes por tipo de esgotamento sanitário do município de Pindoretama/CE.

\begin{tabular}{l|r|r|r|r|r|r}
\hline \multirow{2}{*}{ Tipo de Esgotamento Sanitário } & \multicolumn{2}{|c|}{ Município } & \multicolumn{2}{c|}{ Zona Urbana } & \multicolumn{2}{c}{ Zona Rural } \\
\hline Domicilios & 5.341 & $100 \%$ & 3.259 & $100 \%$ & 2.082 & $100 \%$ \\
\hline Rede pluvial & 13 & $0,24 \%$ & 13 & $0,40 \%$ & 0 & $0,00 \%$ \\
\hline Fossa Séptica & 53 & $0,99 \%$ & 29 & $0,89 \%$ & 24 & $1,15 \%$ \\
\hline Fossa Negra & 5.016 & $93,91 \%$ & 3.123 & $95,83 \%$ & 1.893 & $90,92 \%$ \\
\hline Valas & 45 & $0,84 \%$ & 34 & $1,04 \%$ & 11 & $0,53 \%$ \\
\hline Outros & 30 & $0,56 \%$ & 19 & $0,58 \%$ & 11 & $0,53 \%$ \\
\hline Sem Banheiro e Sanitário & 184 & $3,45 \%$ & 41 & $1,26 \%$ & 143 & $6,87 \%$ \\
\hline Sem Banheiro & 1.407 & $26,34 \%$ & 639 & $19,61 \%$ & 1.065 & $51,15 \%$ \\
\hline
\end{tabular}

Fonte: IBGE (2010).

Conforme SNIS (2016), toda a população urbana do município é contemplada com coleta de resíduos porta a porta, representando $95,5 \%$ da população total. Os resíduos domiciliares coletados são encaminhados para o lixão do município e os resíduos de saúde são levados para Fortaleza para serem incinerados. O município participa do Consórcio Comares, que irá construir um aterro sanitário para a região em conjunto 
com outros municípios. O município de Pindoretama possui como responsável pelo abastecimento de água o Sistema de Autônomo de Água e Esgoto, localizado no distrito-sede.

O SAAE do município atende, atualmente, a população urbana do distrito-sede, possuindo uma ETA do tipo filtração simples, constituída de um reservatório apoiado com capacidade de $300 \mathrm{~m}^{3}$, um reservatório elevado com $198 \mathrm{~m}^{3}$, dois filtros do tipo filtração ascendente, casa de bomba, torre de carga, casa de cloro gasoso e casa de fluoretação. O sistema recebe água bruta do açude Malcozinhado, adutora de $400 \mathrm{~mm}, \mathrm{com}$ vazão de $41,20 \mathrm{l} / \mathrm{s}$ e extensão de $10,40 \mathrm{Km}$. O sistema é do tipo engate rápido de tubos de ferros. O material da adutora apresenta elevada corrosão, havendo diversos problemas de vazamento. A água bruta que chega na ETA entra na torre de carga, local em que é adicionado o coagulante Sulfato de Alumínio, seguindo para os filtros tipo ascendente e, em seguida, encaminhados para o reservatório apoiado, onde é aplicado o cloro. Do reservatório apoiado (RAP), a água tratada é bombeada para o reservatório elevado (REL), que segue para a distribuição por duas redes: uma de DN 300 e outra de DN 100. A ETA tem capacidade de produzir 50 m³/h.

O sistema de bombeamento da ETA do SAAE Pindoretama é constituído de duas bombas, uma principal e uma reserva, com capacidade de bombear até $100 \mathrm{~m}^{3} / \mathrm{h}$. O barrilete possui válvula de retenção, evitando que haja rompimento da tubulação por eventual desligamento rápido do equipamento, e a cloração é do tipo gasosa. Nesse caso, o cloro gasoso é armazenado em cilindros e misturado em uma tubulação por água limpa pressurizada, em que o líquido saturado com o oxidante é encaminhado para um reservatório de polietileno, localizado acima do RAP e gradualmente aplicado na água clarificada. A fluoretação também funciona na parte superior do reservatório apoiado, e a mistura é bombeada até uma caixa de polietileno.

O SAAE de Pindoretama também conta com um laboratório que consegue fazer análises de cor, turbidez e cloro residual. As demais análises para atendimento da Portaria n. ${ }^{\circ}$ 2.914/2011 do Ministério da Saúde são realizadas por uma empresa particular com sede em Fortaleza. Há diversas reclamações sobre o nível elevado de turbidez na água tratada. De acordo com o diretor do SAAE, esse problema deve-se a mudança do manancial de abastecimento. Por vários anos o sistema aduzia água da Lagoa do Tapuio, localizada no município de Aquiraz.

A formação da lagoa em área de dunas resultava em baixa turbidez. Com o período de estiagem, a cidade começou a utilizar as águas do açude Malcozinhado, reservatório eutrofizado e com elevada turbidez. Atualmente, a lagoa é reconhecida como território indígena, fazendo parte da comunidade da Lagoa Encantada, não podendo ser utilizada para outros fins que não sejam demandas para a comunidade indígena.

A dificuldade da ETA em se adaptar à nova fonte hídrica pode estar no processo que antecede a filtração. A coagulação ocorre de forma rápida, dificultando a aglutinação dos microflocos. Caso houvesse o processo de floculação, processo que permite que os microflocos aglutinem-se, tornando-os maiores, tornaria a estação mais resiliente, principalmente aos períodos maiores de estiagem, pois a qualidade do afluente tende a degradar ao longo dos anos. Hipótese não esgota as soluções que podem vir ser adotadas, podendo, também, verificar a possibilidade de aumentar a quantidade de coagulante. O ideal é a contratação de uma empresa especializada para identificação do problema e proposta de solução. Os demais distritos são abastecidos por chafarizes, de responsabilidade da Secretaria de Infraestrutura do Município de Pindoretama, e por poços nas propriedades.

Prognósticos de água e esgoto do município de Pindoretama/CE

Neste prognóstico são apresentadas as proposições para a melhoria e ampliação dos serviços de abastecimento de água e esgotamento sanitário em termos de programas, projetos e ações, com vistas à universalização da prestação desses serviços dentro do horizonte do Plano Municipal de Saneamento Básico. Partindo-se dos dados do IBGE e projetando a população do município a uma taxa de crescimento geométrico de $2,16 \%$ ao ano, obteve-se o número de habitantes do município ano a ano, com o número de 33.988 residentes de final de plano, assim correspondendo, aproximadamente, a 81,9\% de crescimento quando comparado com o ano de 2010. A Figura 1 mostra a representação gráfica da projeção da população e a Tabela 14 apresenta a evolução da população ano a ano no âmbito do município e dos respectivos distritos. 
Figura 1: Gráfico da projeção populacional do município e dos distritos de Pindoretama/CE.

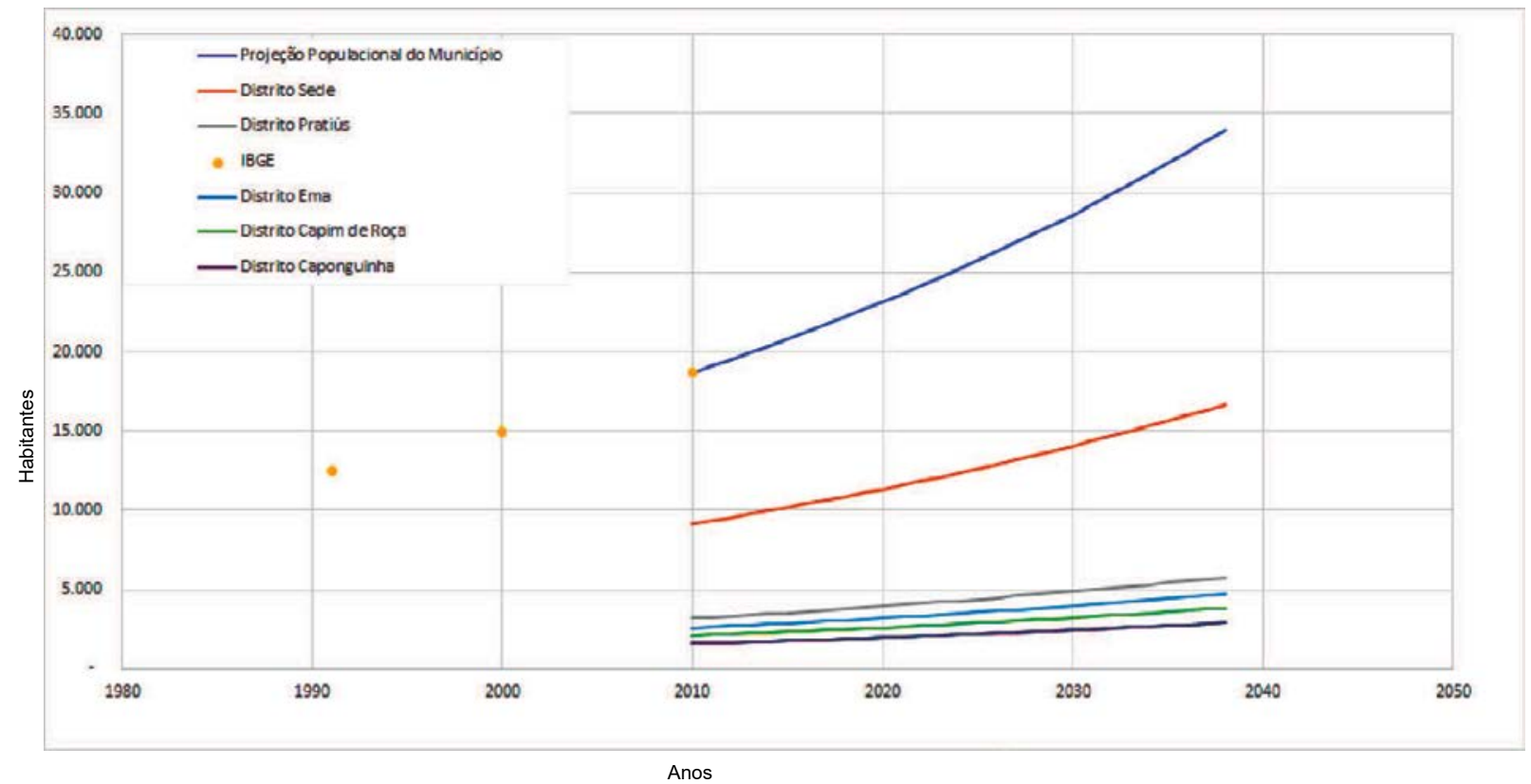

Fonte: Autor (2018).

Tabela 14: Projeção populacional do município de Pindoretama/CE.

\begin{tabular}{|c|c|c|c|c|c|c|c|c|c|c|c|}
\hline \multirow[t]{2}{*}{ Ano } & \multicolumn{2}{|c|}{ Sede } & \multicolumn{2}{|c|}{ Pratiüs } & \multicolumn{2}{|c|}{ Ema } & \multicolumn{2}{|c|}{ Capim de Roça } & \multicolumn{2}{|c|}{ Caponguinha } & \multirow{2}{*}{ Total } \\
\hline & Urbana & Rural & Urbana & Rural & Urbana & Rural & Urbana & Rural & Urbana & Rural & \\
\hline 2010 & 8.998 & 170 & 1.064 & 2.133 & 584 & 2.018 & 590 & 1.521 & 44 & 1.561 & 18.683 \\
\hline 2011 & 9.193 & 174 & 1.107 & 2.159 & 901 & 1.757 & 731 & 1.426 & 556 & 1.084 & 19.087 \\
\hline 2012 & 9.391 & 177 & 1.151 & 2.185 & 937 & 1.778 & 760 & 1.443 & 578 & 1.097 & 19.498 \\
\hline 2013 & 9.595 & 181 & 1.196 & 2.212 & 974 & 1.800 & 790 & 1.461 & 601 & 1.110 & 19.920 \\
\hline 2014 & 9.802 & 185 & 1.243 & 2.239 & 1.012 & 1.822 & 821 & 1.478 & 624 & 1.124 & 20.350 \\
\hline 2015 & 10.014 & 189 & 1.292 & 2.265 & 1.051 & 1.814 & 853 & 1.496 & 619 & 1.137 & 20.790 \\
\hline 2016 & 10.231 & 193 & 1.342 & 2.292 & 1.092 & 1.866 & 886 & 1.513 & 671 & 1.150 & 21.239 \\
\hline 2017 & 10.452 & 197 & 1.393 & 2.319 & 1.134 & 1.887 & 920 & 1.531 & 699 & 1.165 & 21.697 \\
\hline 2018 & 10.678 & 202 & 1.446 & 2.346 & 1.177 & 1.910 & 955 & 1.549 & 726 & 1.178 & 22.161 \\
\hline 2019 & 10.909 & 206 & 1.501 & 2.373 & 1.222 & 1.931 & 991 & 1.567 & 754 & 1.191 & 22.645 \\
\hline 2020 & 11.145 & 211 & 1.557 & 2.401 & 1.268 & 1.953 & 1.028 & 1.585 & 782 & 1.205 & 23.134 \\
\hline 2021 & 11.386 & 215 & 1.616 & 2.427 & 1.315 & 1.976 & 1.067 & 1.603 & 811 & 1.219 & 23.635 \\
\hline 2022 & 11.632 & 220 & 1.675 & 2.455 & 1.364 & 1.998 & 1.106 & 1.621 & 841 & 1.233 & 24.145 \\
\hline 2023 & 11.884 & 225 & 1.737 & 2.482 & 1.414 & 2.020 & 1.147 & 1.639 & 872 & 1.246 & 24.665 \\
\hline 2024 & 12.141 & 229 & 1.801 & 2.509 & 1.466 & 2.042 & 1.180 & 1.657 & 904 & 1.260 & 25.198 \\
\hline 2025 & 12.403 & 234 & 1.866 & 2.537 & 1.519 & 2.065 & 1.232 & 1.676 & 937 & 1.274 & 25.744 \\
\hline 2026 & 12.671 & 239 & 1.934 & 2.564 & 1.574 & 2.087 & 1.277 & 1.693 & 971 & 1.287 & 26.298 \\
\hline 2027 & 12.945 & 245 & 2004 & 2.592 & 1.631 & 2.109 & 1.323 & 1.711 & 1.006 & 1.301 & 26.867 \\
\hline 2028 & 13.225 & 250 & 2075 & 2.620 & 1.689 & 2.132 & 1.370 & 1.730 & 1.042 & 1.315 & 21.448 \\
\hline 2029 & 13.511 & 255 & 2.149 & 2.647 & 1.749 & 2.154 & 1.419 & 1.748 & 1.079 & 1.329 & 28.041 \\
\hline 2030 & 13.804 & 261 & 2.225 & 2.674 & 1.811 & 2.177 & 1.469 & 1.766 & 1.117 & 1.343 & 28.646 \\
\hline 2031 & 14.102 & 266 & 2304 & 2.701 & 1.875 & 2.199 & 1.521 & 1.784 & 1.157 & 1.356 & 29.266 \\
\hline 2032 & 14.407 & 272 & 2385 & 2.728 & 1.941 & 2.221 & 1.575 & 1.801 & 1.197 & 1.370 & 29.897 \\
\hline 2033 & 14.719 & 278 & 2468 & 2.755 & 2.008 & 2.243 & 1.629 & 1.820 & 1.239 & 1.383 & 30.542 \\
\hline 2034 & 15.037 & 284 & 2553 & 2.783 & 2.078 & 2.265 & 1.686 & 1.837 & 1.282 & 1.397 & 31.202 \\
\hline 2035 & 15.362 & 290 & 2.641 & 2.810 & 2.150 & 2.287 & 1.744 & 1.855 & 1.326 & 1.411 & 31.877 \\
\hline 2036 & 15.695 & 297 & 2732 & 2.837 & 2.224 & 2.308 & 1.804 & 1.873 & 1.372 & 1.424 & 32.565 \\
\hline 2037 & 16.034 & 303 & 2826 & 2.863 & 2.300 & 2.330 & 1.866 & 1.890 & 1.419 & 1.437 & 33.268 \\
\hline 2038 & 16.381 & 309 & 2922 & 2.890 & 2.378 & 2.352 & 1.929 & 1.909 & 1.467 & 1.451 & 33.988 \\
\hline
\end{tabular}

Fonte: Autor (2018). 
Projeção da demanda de água e esgoto para o distrito sede do município de Pindoretama/CE:

A projeção da zona urbana do município de Pindoretama apresentou como população total de final de plano 25.386 habitantes, em 2038, que irão demandar uma vazão média de 50,3 l/s, incluindo perdas. Na modelagem, as perdas são reduzidas, gradualmente, de 41,5\% para $29,8 \%$ no final de plano, resultando na manutenção do sistema e do trabalho de melhoria na estação e no combate de fraudes. A demanda por água tratada para a zona urbana do município de Pindoretama será de 60,3 l/s, resultado da vazão máxima diária, de forma a assegurar para a população o per capita de 120 litros de água. A universalização do serviço em toda a zona rural do município ocorrerá em 8 anos, isto é, em 2026, em médio prazo. Na Tabela 15 serão apresentados os estudos de projeção e demanda de água tratada para a sede do município.

Tabela 15: Projeção de demanda de tratamento de água da zona urbana no município de Pindoretama/CE período de $2019-2038$.

\begin{tabular}{|c|c|c|c|c|c|c|c|c|c|c|c|c|}
\hline Anv & $\begin{array}{c}\begin{array}{c}\text { Populaçăo } \\
\text { Total }\end{array} \\
\text {. }\end{array}$ & Cohertura & $\begin{array}{c}\text { População } \\
\text { Atendida }\end{array}$ & Perdas & $\begin{array}{l}\text { Vazão } \\
\text { Média }\end{array}$ & $\begin{array}{c}\text { Vazäo de } \\
\text { Perdas }\end{array}$ & $\begin{array}{c}\text { Vazão } \\
\text { Média Total }\end{array}$ & $\begin{array}{l}\text { Vazăo } \\
\text { Máxłma } \\
\text { Diáría }\end{array}$ & $\begin{array}{l}\text { Vazăn } \\
\text { Máxima } \\
\text { Huráría }\end{array}$ & $\begin{array}{c}\text { Produçäo } \\
\text { Existente }\end{array}$ & $\begin{array}{l}\text { Déficit de } \\
\text { Produçäo }\end{array}$ & $\begin{array}{l}\text { Amplliaçăn } \\
\text { da } \\
\text { Prumluy̆ăn }\end{array}$ \\
\hline & (hab) & $(\%)$ & (hab) & $(\%)$ & $(\mathrm{W} / \mathrm{s})$ & (L/s) & $(\mathrm{L} / \mathrm{s})$ & (L/s) & $(\mathrm{L} / \mathrm{s})$ & $(\mathrm{L} / \mathrm{s})$ & $(\mathrm{L} / \mathrm{s})$ & $(\mathrm{L} / \mathrm{s})$ \\
\hline 2019 & 15.377 & 86,8 & 13.341 & 41,5 & 18,5 & 13,1 & 31,7 & 38,0 & 57,0 & 13,9 & $-24,1$ & 0,0 \\
\hline 2020 & 15.990 & 86,8 & 13.873 & 40,9 & 19,3 & 13,3 & 32,6 & 39,1 & 58,7 & 13,9 & $-25,2$ & 0,0 \\
\hline 2021 & 16.410 & 86,8 & 14.237 & 40,3 & 19,8 & 13,3 & 33,1 & 39,7 & 59,6 & 13,9 & $-25,8$ & 0,0 \\
\hline 2022 & 16838 & 86,8 & 14.615 & 39,7 & 20,3 & 13,3 & 33,6 & 40,4 & 60,5 & 13,9 & $-26,5$ & 0,0 \\
\hline 2023 & 17.278 & 86,8 & 14.997 & 39,0 & 20,8 & 13,3 & 34,2 & 41,0 & 61,5 & 13,9 & 27,1 & 0,0 \\
\hline 2024 & 17.730 & 86,8 & 15.390 & 38,4 & 21,4 & 13,3 & 34,7 & 41,7 & 62,5 & 13,9 & $-27,8$ & 0,0 \\
\hline 2025 & 18192 & 86,8 & 15790 & 37,8 & 21,9 & 13,3 & 35,3 & 42,3 & 63,5 & 13,9 & $-28,4$ & 0,0 \\
\hline 2026 & 18.667 & 100,0 & 18.667 & 37,2 & 25,9 & 15,4 & 41,3 & 49,5 & 74,3 & 13,9 & 35,7 & 46,4 \\
\hline 2027 & 19.154 & 100,0 & 19.154 & 36,6 & 26,6 & 15,4 & 42,0 & 50,4 & 75,5 & 60,3 & 9,2 & 0,0 \\
\hline 2028 & 19651 & 100,0 & 19651 & 36,0 & 27,3 & 15,3 & 42,6 & 51,2 & 76,7 & 60,3 & 9,1 & 0,0 \\
\hline 2029 & 20.163 & 100,0 & 20.163 & 35,4 & 28,0 & 15,3 & 43,3 & 52,0 & 78,0 & 60,3 & 8,3 & 0,0 \\
\hline 2030 & 20.686 & 100,0 & 20.686 & 34,8 & 28,7 & 15,3 & 44,0 & 52,8 & 79,3 & 60,3 & 7,4 & 0,0 \\
\hline 2031 & 21226 & 100,0 & 2122.6 & 34,1 & 29,5 & 15,3 & 44,8 & 53,7 & 80,6 & 60,3 & 6,6 & 0,0 \\
\hline 2032 & 21.777 & 100,0 & 21.777 & 33,5 & 30,2 & 15,3 & 45,5 & 54,6 & 81,9 & 60,3 & 5,7 & 0,0 \\
\hline 2033 & 22.341 & 100,0 & 22.341 & 32,9 & 31,0 & 15,2 & 46,2 & 55,5 & 83,2 & 60,3 & 4,8 & 0,0 \\
\hline 2034 & 22.920 & 100,0 & 22.920 & 32,3 & 31,8 & 15,2 & 47,0 & 56,4 & 84,6 & 60,3 & 3,9 & 0,0 \\
\hline 2035 & 23.514 & 100,0 & 23.514 & 31,7 & 32,7 & 15,1 & 47,8 & 57,4 & 86,0 & 60,3 & 2,9 & 0,0 \\
\hline 2036 & 24.123 & 100,0 & 24.123 & 31,1 & 33,5 & 15,1 & 48,6 & 58,3 & 87,5 & 60,3 & 2,0 & 0,0 \\
\hline 2037 & 24.748 & 100,0 & 24.748 & 30,5 & 34,4 & 15,0 & 49,4 & 59,3 & 89,0 & 60,3 & 1,0 & 0,0 \\
\hline 2038 & 25.386 & 100,0 & 25.386 & 29,8 & 35,3 & 15,0 & 50,3 & 60,3 & 90,5 & 60,3 & 0,0 & 0,0 \\
\hline
\end{tabular}

Fonte: Autor (2018).

No que diz respeito à reservação de água, atualmente, a zona urbana apresenta um déficit de 596 metros cúbicos de reservatórios. Para que se atinja a demanda necessária para o período de 20 anos, deverão ser construídos mais reservatórios, de forma que somem 1.737 metros cúbicos, assim atingindo a demanda para final de plano, em 2038. Na Tabela 16 são apresentados os dados da demanda urbana por reservação. 
Tabela 16: Projeção de demanda de reservação de água da zona urbana no município de Pindoretama/CE período de 2019 - 2038.

\begin{tabular}{|c|c|c|c|c|c|c|c|c|c|}
\hline Ano & $\begin{array}{c}\text { Populaçáo } \\
\text { Total }\end{array}$ & Cobertura & $\begin{array}{c}\text { Populaçăo } \\
\text { Atendida }\end{array}$ & \begin{tabular}{|c|} 
Vazăo \\
Máxtma \\
Diária
\end{tabular} & $\begin{array}{c}\text { Vazăo } \\
\text { Máxima } \\
\text { Horária }\end{array}$ & $\begin{array}{c}\text { Demanda } \\
\text { Reservacäo }\end{array}$ & $\begin{array}{c}\text { Reservaçăo } \\
\text { Existente }\end{array}$ & $\begin{array}{c}\text { Déflctt de } \\
\text { Reservacäo }\end{array}$ & $\begin{array}{c}\text { Ampliaçăo } \\
\text { da } \\
\text { Reservacäo }\end{array}$ \\
\hline & (hab) & (\%) & (hab) & $(\mathrm{L} / \mathrm{S})$ & $(\mathrm{L} / \mathrm{S})$ & $\left(\mathrm{m}^{3}\right)$ & $\left(\mathrm{m}^{5}\right)$ & $\left(\mathrm{m}^{5}\right)$ & $\left(m^{5}\right)$ \\
\hline 2019 & 15.377 & 86,8 & 13.341 & 38 & 57 & 1.094 & 498 & -596 & 0 \\
\hline 2020 & 15.990 & 86,8 & 13.873 & 39 & 59 & 1.126 & 498 & -628 & 0 \\
\hline 2021 & 16.410 & 86,8 & 14.237 & 40 & 60 & 1.144 & 498 & .646 & 0 \\
\hline 2022 & 16.838 & 86.8 & 14.615 & 40 & 61 & 1.162 & 498 & -664 & 0 \\
\hline 2023 & 17.278 & 86,8 & 14.997 & 41 & 62 & 1.181 & 498 & -683 & 0 \\
\hline 2024 & 17.730 & 86.8 & 15.390 & 42 & 62 & 1.200 & 498 & -702 & 0 \\
\hline 2025 & 18192 & 86,8 & 15790 & 42. & 63 & 1219 & 498 & -72.1 & 0 \\
\hline 2026 & 18.667 & 100.0 & 18.667 & 50 & 74 & 1.427 & 498 & 929 & 1.239 \\
\hline 2027 & 19.154 & 100,0 & 19.154 & 50 & 76 & 1.450 & 1.737 & 287 & 0 \\
\hline 2028 & 19.651 & 100,0 & 19.651 & 31 & 71 & 1.474 & 1.737 & 263 & 0 \\
\hline 2029 & 20.163 & 100.0 & 20.163 & 52 & 78 & 1.497 & 1.737 & 240 & 0 \\
\hline 2030 & 20.686 & 100,0 & 20.636 & 53 & 79 & 1.522 & 1.737 & 215 & 0 \\
\hline 2031 & 21.226 & 100,0 & 21.226 & 54 & 81 & 1.547 & 1.737 & 190 & 0 \\
\hline 2032 & 2.1777 & 100,0 & $2.1 \mathrm{~m}$ & 55 & 82. & 1572. & 1737 & 165 & 0 \\
\hline 2033 & 22.341 & 100.0 & 22.341 & 55 & 83 & 1.598 & 1.737 & 139 & 0 \\
\hline 2034 & 22.920 & 100,0 & 22.920 & 56 & 85 & 1.625 & 1.737 & 112 & 0 \\
\hline 2035 & 23.514 & 100.0 & 23.514 & 57 & 86 & 1.652 & 1.737 & 85 & 0 \\
\hline 2036 & 24.123 & 100,0 & 24.123 & 58 & 87 & 1.680 & 1.737 & 57 & 0 \\
\hline 2037 & 24.748 & 100.0 & 24.748 & 59 & 89 & 1.708 & 1.737 & 29 & 0 \\
\hline 2038 & 25.386 & 100,0 & 25.386 & 60 & 90 & 1.737 & 1.737 & 0 & 0 \\
\hline
\end{tabular}

Fonte: Autor (2018).

Ao longo do período do plano, isto é, 20 anos, o número de economias crescerá em, aproximadamente, $90 \%$. Estima-se que, por meio de programas de manutenção, haverá substituição de hidrômetros a cada 5 anos, de forma a diminuir perdas no sistema. Em 2038, estimam-se 7.253 economias na zona urbana do município, todas com hidrômetros. Na Tabela 17 será apresentada a evolução das economias e do índice de hidrometração neste período. 
Tabela 17: Projeção da demanda de ligações da água da zona urbana no município de Pindoretama/CE período de 2019 - 2038.

\begin{tabular}{|c|c|c|c|c|c|c|c|c|c|}
\hline Ano & \begin{tabular}{|c} 
Populaçäo \\
Total
\end{tabular} & Cobertura & $\begin{array}{c}\text { Populaçăo } \\
\text { Atendida }\end{array}$ & Ligacöes & $\begin{array}{c}\text { Ligaçños } \\
\text { incrementais } \\
\text { com } \\
\text { hidrômetros }\end{array}$ & $\begin{array}{c}\text { Índice de } \\
\text { hidrometracăo }\end{array}$ & $\begin{array}{c}\begin{array}{c}\text { Número de } \\
\text { ligaçöes } \\
\text { hidrometradas }\end{array} \\
\end{array}$ & $\begin{array}{c}\text { Déficit de } \\
\text { Hidrômetros }\end{array}$ & $\begin{array}{c}\begin{array}{c}\text { Substituição } \\
\text { de }\end{array} \\
\text { Hidrômetros }\end{array}$ \\
\hline & (hab) & $(\%)$ & (hab) & (un) & (un) & $(\%)$ & (un) & (un) & (un) \\
\hline 2019 & 15.377 & 86,8 & 13.341 & 3.812 & 0 & 90,6 & 3.454 & 358 & 0 \\
\hline 2020 & 15.990 & 86,8 & 13.873 & 3.964 & 152 & 90,6 & 3.592 & 372 & 180 \\
\hline 2021 & 16.410 & 86.8 & 14.237 & 4.068 & 104 & 90,6 & 3.686 & 382 & 184 \\
\hline 2022 & 16.838 & 86.8 & 14.615 & 4.176 & 108 & 100.0 & 4.176 & 0 & 3.704 \\
\hline 2023 & 17.278 & 86,8 & 14.997 & 4.285 & 109 & 100,0 & 4.285 & 0 & 108 \\
\hline 2024 & 17.730 & 86,8 & 15.390 & 4.397 & 112 & 100,0 & 4.397 & 0 & 109 \\
\hline 2025 & 18.192 & 86,8 & 15.790 & 4.511 & 114 & 100,0 & 4.511 & 0 & 292 \\
\hline 2026 & 18.667 & 100,0 & 18.667 & 5.333 & 822 & 100,0 & 5.333 & 0 & 299 \\
\hline 2027 & 19.154 & 100,0 & 19.154 & 5.473 & 139 & 100,0 & 5.473 & 0 & 4.526 \\
\hline 2028 & 19.651 & 100.0 & 19.651 & 5.615 & 142 & 100.0 & 5.615 & 0 & 247 \\
\hline 2029 & 20.163 & 100,0 & 20.163 & 5.761 & 146 & 100,0 & 5.761 & 0 & 251 \\
\hline 2030 & 20.686 & 100.0 & 20.686 & 5.910 & 150 & 100,0 & 5.910 & 0 & 438 \\
\hline 2031 & 21.226 & 100,0 & 21.226 & 6.064 & 154 & 100,0 & 6.064 & 0 & 448 \\
\hline 2032 & 21.777 & 100,0 & 21.777 & 6.222 & 158 & 100,0 & 6.222 & 0 & 4.680 \\
\hline 2033 & 22.341 & 100,0 & 22.341 & 6.383 & 161 & 100,0 & 6.383 & 0 & 405 \\
\hline 2034 & 22.920 & 100,0 & 22.920 & 6.549 & 166 & 100,0 & 6.549 & 0 & 412 \\
\hline 2035 & 23.514 & 100,0 & 23.514 & 6.718 & 170 & 100,0 & 6.718 & 0 & 603 \\
\hline 2036 & 24.123 & 100,0 & 24.123 & 6.892 & 174 & 100,0 & 6.892 & 0 & 618 \\
\hline 20.37 & 24.748 & 100,0 & 24.748 & 7.071 & 179 & 100,0 & 7.071 & 0 & 4.854 \\
\hline 2038 & 25.386 & 100,0 & 25.386 & 7.253 & 182 & 100,0 & 7.253 & 0 & 583 \\
\hline
\end{tabular}

Fonte: Autor (2018).

A rede de distribuição de água do município terá um aumento de $93 \%$ durante o horizonte do plano, com extensão total de 57.878 metros. No que concerne ao esgotamento sanitário do município, atualmente, há somente soluções individuais de esgotamento, inadequadas, em que os efluentes domésticos são despejados em fossas negras ou no sistema de drenagem. Tendo em vista atender às condições adequadas de saúde e de proteção ao meio ambiente, a sede do município necessita uma ETE com capacidade de tratamento de 20,5 l/s para atender à população desse planejamento. Na Tabela 17 é apresentada a demanda de atendimento em médio e longo prazo de tratamento de efluente sanitário para o distrito-sede. Será necessária a instalação de 38.626 metros de rede de esgoto para atender toda a população do horizonte de planejamento.

Atualmente, $77,7 \%$ da população da zona rural do município, exceto do distrito-sede, apresentam soluções individuais adequadas de abastecimento de água. Entende-se como adequadas o uso de poços, nascentes 
ou cisternas que tenham canalização interna para o domicílio. Essa porcentagem é basicamente de poços particulares, conforme censo do IBGE, e está extrapolado para o atual período. Os demais habitantes são abastecidos por soluções individuais ou coletivas inadequadas, como chafarizes, nascentes que não estão dentro da propriedade e uso de carro-pipa (IBGE, 2011). No plano, deseja-se atingir $100 \%$ da população com soluções individuais adequadas de abastecimento de água. Para tal, os demais $22,3 \%$ da população irão receber, em até 4 anos (curto prazo), cisternas com canalização interna no domicílio, de forma a universalizar o acesso à água com segurança hídrica e em quantidade adequada. Na Tabela 17 é apresentada a demanda de soluções individuais de água na zona rural. O município deverá, também, realizar estudo para verificar a possibilidade de implantar sistemas rurais para pequenas comunidades.

O Programa Água para Todos, do Governo Federal, considera pequenas comunidades como aquela que apresenta no mínimo 40 famílias. No tocante ao esgotamento sanitário, verifica-se que $51,15 \%$ da população rural não possui banheiro de uso exclusivo para os residentes do domicílio e que $6,87 \%$ não possuem banheiro e sanitário. Dessa maneira, propõe-se que o município promova um programa de construção de banheiro, com metas de redução para $41,15 \%$ em curto prazo, 31,15\% em médio prazo e zerar o número de habitantes sem banheiro em longo prazo.

No que diz respeito ao tratamento dos efluentes da zona rural, somente 1,15\% dos domicílios possuem fossa sépticas, estando os demais lançando em fossas rudimentares, que não possuem sistema de filtração e não trata adequadamente o efluente, contaminando o solo e o lençol freático. No planejamento, espera-se, em curto prazo elevar para $25 \%$ os habitantes que despejam seus efluentes em fossa sépticas, alcançando $35 \%$ em médio prazo e chegando a $70 \%$ no final de plano.

Metas e investimentos para o abastecimento de água do município de Pindoretama no período de 2019 - 2038: Como resultado da evolução das demandas do município de Pindoretama e da população, que se deseja atender no período de planejamento, encontram-se os indicadores de água, que representa o percentual da população que será atendida com o serviço no horizonte do plano. Na Tabela 18 serão apresentadas as metas para a universalização do abastecimento de água na zona urbana e rural.

Tabela 18: Meta para os indicadores de abastecimento de água do município de Pindoretama/CE no período 2019 -2038.

\begin{tabular}{l|c|c|c|c}
\hline \multirow{2}{*}{ Indicador Água (\%) } & \multicolumn{4}{c}{ Meta } \\
\cline { 2 - 5 } & Atual & $\mathbf{2 0 1 9 - 2 0 2 2}$ & $\mathbf{2 0 2 3 - 2 0 2 6}$ & $\mathbf{2 0 2 7 - 2 0 3 8}$ \\
\hline Índice de cobertura de água da zona urbana do distrito Sede & 97,5 & 100,0 & 100,0 & 100,0 \\
\hline Índice de cobertura de água da zona urbana do do distrito Pratius & 0,0 & 0,0 & 100,0 & 100,0 \\
\hline Índice de cobertura de água da zona urbana do do distrito EMA & 0,0 & 0,0 & 100,0 & 100,0 \\
\hline Índice de cobertura de água da zona urbana do do distrito Capim de Roça & 0,0 & 0,0 & 100,0 & 100,0 \\
\hline Índice de cobertura de água da zona urbana do do distrito Caponguinha & 0,0 & 0,0 & 100,0 & 100,0 \\
\hline Índice de cobertura de água da zona urbana do Município & 86,8 & 86,8 & 100,0 & 100,0 \\
\hline População rural atendida com soluções individuais de água adequadas & 77,67 & 100 & 100,0 & 100,0 \\
\hline
\end{tabular}

Fonte: Autor (2018).

Do índice de cobertura resultam as metas físicas, que quantificam as quantidades específicas de rede, estações de tratamento, de reservação e ligações que serão realizados no período. A Tabela 19 traz metas física estimadas para o município para o período de 2019 a 2038. 
Tabela 19: Metas físicas de abastecimento de água do município de Pindoretama/CE período $2019-2038$

\begin{tabular}{|c|c|c|c|c|}
\hline Meta Fisica Ảgua & Atual & $2019-2022$ & $2023-2026$ & $2027-2038$ \\
\hline Substituiçâo da atual adutora de água bruta (Km) & 10,4 & & 10,4 & \\
\hline Ampliaçáo da capacidade de produçáo de água tratada da ETA da SEDE (L) & 13,9 & 25,8 & 25,8 & 25,8 \\
\hline Ampliaçáo da capacidade de reservaçáo de água do Distrito Sede $\left(\mathrm{m}^{3}\right)$ & 498,0 & 498,0 & 644 & 644 \\
\hline Ligações com Hidrômetros no Distrito Sede (Unidade) & $2.753,0$ & 3.386 & 3.689 & 4.769 \\
\hline Ampliação da Rede de Abastecimento de Água do Distrito Sede (m) & 30.000 & 32.821 & 35.272 & 44.019 \\
\hline $\begin{array}{l}\text { Instalação de Sistema de Abastecimento Água para a Zona Urbana do } \\
\text { Distrito Pratiús (Unidade) }\end{array}$ & 0,0 & & 1 & \\
\hline $\begin{array}{l}\text { Instalação de Sistema de Abastecimento Água para a Zona Urbana do } \\
\text { Distrito Ema (Unidade) }\end{array}$ & 0,0 & & 1 & \\
\hline $\begin{array}{l}\text { Instalaçáo de Sistema de Abastecimento Água para a Zona Urbana do } \\
\text { Distrito Capim de Roça (Unidade) }\end{array}$ & 0,0 & & 1 & \\
\hline $\begin{array}{l}\text { Instalação de Sistema de Abastecimento Água para a Zona Urbana do } \\
\text { Distrito Caponguinha (Unidade) }\end{array}$ & 0,0 & & 1 & \\
\hline Instalaçáo de Cistemas na Zona Rural (unidades) & 0,0 & 0 & 79 & 971 \\
\hline
\end{tabular}

Fonte: Autor (2018).

Para que sejam atingidas as metas propostas para o município no que se refere ao abastecimento de água, será necessário um montante de $R \$ 21.703 .059,18$, distribuído em curto $(R \$ 4.434 .709,77)$, médio ( $R \$$ $15.037 .700,59)$ e longo prazo $(R \$ 2.230 .648,81)$. Na Tabela 20 é apresentado o orçamento para cada meta e o desembolso conforme período.

Tabela 20: Estimativa de investimento para atingir as metas de abastecimento de água do município de Pindoretama/CE período 2019 - 2038.

\begin{tabular}{|c|c|c|c|c|c|c|c|c|}
\hline \multirow{3}{*}{$\begin{array}{l}\text { Meta Fisica Água } \\
\text { Substituição da atual adutora de água bruta }\end{array}$} & \multicolumn{8}{|c|}{ Investimento } \\
\hline & \multicolumn{2}{|c|}{$2019-2022$} & \multicolumn{2}{|c|}{$2023 \cdot 2026$} & \multicolumn{2}{|c|}{$2027-2038$} & \multicolumn{2}{|r|}{ Total } \\
\hline & R\$ & . & RS & $921.302,15$ & R\$ & . & R\$ & $921.302,15$ \\
\hline Ampliação da capacidade de produção de àgua tratada da ETA da SEDE (L & R\$ & $780.217,11$ & R\$ & . & RS & - & RS & $780.217,11$ \\
\hline Ampliação da capacidade de reservação de ȧgua do Distrito Sede ( $\left(\mathrm{m}^{3}\right)$ & R\$ & . & RS & $445.838,35$ & R\$ & . & R\$ & $445.838,35$ \\
\hline Ligações com Hidrômetros no Distrito Sede (Unidade) & RS & $42.940,86$ & R\$ & $37.301,95$ & R\$ & $133.122,69$ & RS & $213.365,49$ \\
\hline Ampliação da Rede de Abastecimento de Água do Distrito Sede (m) & RS & $67.295,37$ & R\$ & $58.458,28$ & R\$ & $208.625,11$ & R\$ & $334.378,76$ \\
\hline $\begin{array}{l}\text { Instalaç̃o de Sistema de Abastecimento Água para a Zona Urbana do } \\
\text { Distrito Pratüs (Unidade) }\end{array}$ & RS & . & RS & $4.349 .572,32$ & R\$ & - & R\$ & $4.349 .572,32$ \\
\hline $\begin{array}{l}\text { Instalação de Sistema de Abastecimento Água para a Zona Urbana do } \\
\text { Distrito Ema (Unidade) }\end{array}$ & R\$ & . & R\$ & $3.539 .795,68$ & R\$ & . & R\$ & $3.539 .795,68$ \\
\hline $\begin{array}{l}\text { Instalação de Sistema de Abastecimento Água para a Zona Urbana do } \\
\text { Distrito Capim de Roça (Unidade) }\end{array}$ & R\$ & - & RS & $2.871 .432,24$ & RS & . & R\$ & $2.871 .432,24$ \\
\hline $\begin{array}{l}\text { Instalaç̃o de Sistema de Abastecimento Água para a Zona Urbana do } \\
\text { Distrito Caponguinha (Unidade) }\end{array}$ & R\$ & . & RS & $2.183 .717,52$ & RS & - & R\$ & $2.183 .717,52$ \\
\hline Instalação de Cisternas na Zona Rural (unidades) & RS & $3.544 .256,44$ & RS & $630.282,11$ & Rs & $1.888 .901,01$ & R\$ & $6.063 .439,56$ \\
\hline Total & & 4.434.709,77 & RS & $5.037 .700,59$ & RS 2 & $2.230 .648,81$ & $\mathrm{R} \$$ & $1.703 .059,18$ \\
\hline
\end{tabular}

Fonte: Autor (2018). 
Metas e investimentos para o esgotamento sanitário do município de Pindoretama/CE para o período de 2019 - 2038: Assim como para o abastecimento de água, foram propostas metas de indicadores para esgotamento sanitário, que são apresentados na Tabela 21.

Tabela 21: Meta para os indicadores de esgotamento sanitário do município de Pindoretama/CE período 2019 - 2038.

\begin{tabular}{|c|c|c|c|c|}
\hline \multirow{2}{*}{ Indicador Esgoto (\%) } & \multicolumn{4}{|c|}{ Meta } \\
\hline & Atual & $2019-2022$ & $2023-2026$ & $2027-2038$ \\
\hline $\begin{array}{l}\text { Índice de cobertura de esgotamento sanitário da zona urbana do } \\
\text { Município }\end{array}$ & 0,0 & 0,0 & 100,0 & 100,0 \\
\hline $\begin{array}{l}\text { População rrbana com banheiro exclusivo dos residentes do } \\
\text { domicilios }\end{array}$ & 80,4 & 90,4 & 100,0 & 100,0 \\
\hline $\begin{array}{l}\text { População rural atendida com soluções individuais de } \\
\text { esgotamento sanitário adequadas }\end{array}$ & 1,15 & 25,00 & 35,0 & 70,0 \\
\hline $\begin{array}{l}\text { População rural com banheiro exclusivo dos residentes do } \\
\text { domicilios }\end{array}$ & 48,85 & 58,85 & 68,9 & 100,0 \\
\hline
\end{tabular}

Fonte: Autor (2018).

Já na Tabela 22 são apresentadas as metas físicas a serem atingidas durante o período de 2019 a 2038. Busca-se instalar uma ETE em cada distrito e a universalização do acesso a banheiros, com instalação de fossa sépticas na zona rural e em áreas mais isoladas.

Tabela 22: Metas físicas de esgotamento sanitário do município de Pindoretama/CE período 2019 $-2038$.

\begin{tabular}{l|c|c|c}
\multicolumn{1}{c|}{ Meta Física Esgoto } & Atual & $2019-2022$ & $2023-2026$ \\
\hline $\begin{array}{l}\text { Instalação de Sistema de Abastecimento es gotamento sanitário } \\
\text { para a Zona Urbana do Distrito Sede (Unidade) }\end{array}$ & 0 & $2027-2038$ & 1 \\
\hline $\begin{array}{l}\text { Instalação de Sistema de Abastecimento esgotamento sanitário } \\
\text { para a Zona Urbana do Distrito Pratiús (Unidade) }\end{array}$ & 0,0 & 1 \\
\hline $\begin{array}{l}\text { Instalação de Sistema de Abastecimento esgotamento sanitário } \\
\text { para a Zona Urbana do Distrito Ema (Unidade) }\end{array}$ & 0,0 & 1 \\
\hline $\begin{array}{l}\text { Instalação de Sistema de Abastecimento esgotamento sanitário } \\
\text { para a Zona Urbana do Distrito Capim de Roça (Unidade) } \\
\text { Instalação de Sistema de Abastecimento esgotamento sanitário } \\
\text { para a Zona Urbana do Distrito Caponguinha (Unidade) }\end{array}$ & 0,0 & 0 & 1 \\
\hline \begin{tabular}{l} 
Instalação de Fossa Sépticas na Zona Rural (unidades) \\
\hline Construção de banheiros (unidades)
\end{tabular} & 0 & 53 & 1 \\
\hline
\end{tabular}

Fonte: Autor (2018).

Quanto ao orçamento estimado para ao atendimento das metas de esgotamento sanitário, será necessário o montante de $R \$ 73.860 .116,23$, distribuído em curto $(R \$ 8.135 .632,68)$, médio $(R \$ 52.901 .892,61)$ e longo prazo $(R \$ 12.822 .590,94)$. Na Tabela 23 é apresentado o orçamento para cada meta e o desembolso conforme período. 
Tabela 23: Estimativa de investimento para atingir as metas de esgotamento sanitário do município de Pindoretama/CE período 2019 - 2038.

\begin{tabular}{|c|c|c|c|c|c|c|c|c|}
\hline \multirow{2}{*}{ Meta Fisica } & \multicolumn{8}{|c|}{ Investimento } \\
\hline & \multicolumn{2}{|c|}{$2019-2022$} & \multicolumn{2}{|r|}{$2023-2026$} & \multicolumn{2}{|c|}{$2027-2038$} & \multicolumn{2}{|r|}{ Total } \\
\hline $\begin{array}{l}\text { Instalação de Sistema de Abastecimento esgotamento sanitário } \\
\text { para a Zona Urbana do Distrito Sede (Unidade) }\end{array}$ & $\mathrm{RS}$ & - & RS & $28.007 .585,45$ & RS & - & $\mathrm{RS}$ & $28.007 .585,45$ \\
\hline $\begin{array}{l}\text { Instalação de Sistema de Abastecimento esgotamento sanitário } \\
\text { para a Zona Urbana do Distrito Pratiús (Unidade) }\end{array}$ & RS & - & RS & $4.903 .349,76$ & RS & - & $\mathrm{RS}$ & $4.903 .349,76$ \\
\hline $\begin{array}{l}\text { Instalação de Sistema de Abastecimento es gotamento sanitário } \\
\text { para a Zona Urbana do Distrito Ema (Unidade) }\end{array}$ & $\mathrm{RS}$ & - & RS & $3.990 .474,24$ & RS & - & $\mathrm{R} S$ & $3.990 .474,24$ \\
\hline $\begin{array}{l}\text { Instalaçâo de Sistema de Abastecimento es gotamento sanitário } \\
\text { para a Zona Urbana do Distrito Capim de Roça (Unidade) }\end{array}$ & RS & - & RS & $3.237 .016,32$ & RS & - & $\mathrm{RS}$ & $3.237 .016,32$ \\
\hline $\begin{array}{l}\text { Instalaçấo de Sistema de Abastecimento es gotamento sanitário } \\
\text { para a Zona Urbana do Distrito Caponguinha (Unidade) }\end{array}$ & RS & - & RS & $2.461 .743,36$ & RS & - & $\mathrm{RS}$ & $2.461 .743,36$ \\
\hline Instalação de Fossa Sépticas na Zona Rural (unidades) & RS & $175.812,66$ & RS & $850.188,01$ & RS & $3.374 .715,59$ & $\mathrm{RS}$ & $4.400 .716,25$ \\
\hline Construção de banheiros (unidades) & RS & $7.959 .820,03$ & RS & $9.451 .535,47$ & RS & $9.447 .875,35$ & $\mathrm{RS}$ & $26.859 .230,85$ \\
\hline Total & RS & $8.135 .632,68$ & RS & $52.901 .892,61$ & RS & $2.822 .590,94$ & RS & $73.860 .116,23$ \\
\hline
\end{tabular}

Fonte: Autor (2018).

\section{Conclusão}

O Plano Municipal de Saneamento Básico, exigência da Lei Federal n. ${ }^{\circ 11.445 / 2007}$, é a chave para obter recursos do Governo Federal para o setor, não sendo possível a realização de obras e serviços de saneamento no âmbito municipal para os municípios que não possuem o referido documento, caso do município de Pindoretama/CE. Para melhor acompanhamento do crescimento, o Sistema Autônomo de Água e Esgoto deverá ampliar a ETA existente, que abastece a sede do município, para atender uma população de horizonte de planejamento de 16.690 habitantes, com demanda futura de 39,7 l/s. Nos distritos de Pratiús, Ema, Capim de Roça e Caponguinha, deverá instalar uma estação de tratamento de água para atender à população em quantidade e qualidade. Já nas zonas rurais dos distritos deverão proceder com o fornecimento de cisternas dimensionadas, de forma a garantir a segurança hídrica dos usuários com a canalização interna. O custo total para as melhorias no abastecimento de água é estimado em $\mathrm{R} \$ 21.703 .059,18$. No que concerne o esgotamento sanitário, o município não possui sistema de esgotamento sanitário, sendo, aproximadamente, 99\% dos efluentes domésticos gerados no município despejados de forma inadequada, e o restante (1\%) é lançado em fossas sépticas. Para sanar a deficiência o município, este deverá instalar estações de tratamento para as zonas urbanas dos 5 distritos, que são regiões mais adensadas. Para as zonas rurais, construir fossas sépticas, desativando as fossas negras e cessando o lançamento de efluentes em ruas e galerias. Além de fornecer, ao longo de 20 anos, kits de banheiro para a população de baixa renda. O orçamento estimado para esta meta de esgotamento para o município é de $R \$ 73.860 .116,23$. A estimativa prévia de investimento para o município, para que possam atingir as metas de abastecimento de água e esgotamento sanitário propostas pelo presente trabalho, é de $\mathrm{R} \$ 95,6$ milhões

À luz do exposto, infere-se que o PMSB é fundamental para o município de Pindoretama, para que este possa planejar ações para a melhoria da qualidade de vida da população a partir do ingresso nos programas do Governo Federal para tal finalidade. 


\section{Referências}

BRASIL. Decreto $n^{\circ} 7.217$, de 21 de junho de 2010. Regulamenta a Lei no 11.445 , de 5 de janeiro de 2007. Diário Oficial da República Federativa do Brasil, Brasília, DF, 21 jun. 2010, p. 3, col. 1. Disponível em: http://www.planalto.gov.br/ccivil_03/_ato2007-2010/2010/decreto/d7217.htm. Acesso em: 08 maio 2018.

BRASIL. Lei no 11.445, de 05 de janeiro de 2007. Estabelece as diretrizes nacionais para o saneamento básico. Diário Oficial da República Federativa do Brasil, Brasília, DF, 08 jan.

2007, p. 3, col.1. Disponível em: http://www.planalto.gov.br/ccivil_03/_ato2007-2010/2007/lei/l11445.htm. Acesso em: 20 maio 2018.

CEARÁ. Assembleia Legislativa. Coleção Cadernos Regionais do Pacto das Águas. Fortaleza: INESP, 2009. v. 9.

CONSDUCTOR ENGENHARIA. Plano Municipal de Saneamento Básico do Município de Caucaia. Fortaleza: Consductor Engenharia, 2014.

CONSELHO ESTADUAL DO MEIO AMBIENTE. Resolução $\mathbf{n}^{\circ}$ 02, de 2 de fevereiro de 2017. Dispõe sobre padrões e condições para lançamento de efluentes líquidos gerados por fontes poluidoras, revoga as Portarias SEMACE $n^{\circ} 154$, de 22 de julho de 2002, e $n^{\circ} 111$, de 5 de abril de 2011, e altera a Portaria SEMACE n 151, de 25 de novembro de 2002. Ceará: COEMA, 2017.

SANTOS FILHO, A. Estudo de caso do Programa Água para Todos do Ministério da Integração Nacional. 2014. 48 f. Monografia (Especialização em Gestão Pública) - Universidade Cândido Mendes, Rio de Janeiro, 2014.

FUNDAÇÃO NACIONAL DE SAÚDE. Termo de referência para elaboração de planos municipais de saneamento básico. Brasília: FUNASA, 2012.

HELLER, L; PÁDUA, V. L. de. Abastecimento de água para consumo humano. Belo Horizonte: Editora UFMG, 2016.

INSTITUTO BRASILEIRO DE MEIO AMBIENTE E DOS RECURSOS NATURAIS RENOVÁVEIS. Cadernos de formação - volume 1: Política Nacional de Meio Ambiente. Brasília: Ministério do Meio Ambiente, 2006. INSTITUTO BRASILEIRO DE GEOGRAFIA E ESTATÍSTICA. Base de informações do Censo Demográfico 2010: resultados do universo por setor censitário. Rio de Janeiro: IBGE, 2011.

INSTITUTO DE PESQUISA ECONÔMICA APLICADA. Diagnóstico do resíduos sólidos urbanos. Brasília: IPEA, 2012.

INSTITUTO DE PESQUISA E ESTRATÉGIA ECONÔMICA DO CEARÁ. Perfil Básico Municipal 2017 - Pindoretama. Fortaleza: IPECE, 2018.

JORDÃO, E. P.; PESSOA, C. A. Tratamento de esgotos domésticos. 7. ed. Rio de Janeiro: ABES, 2014. BRASIL. Ministério das Cidades. Curso EAD Planos de Saneamento Básico, modulo 2. Brasília: Ministério das Cidades/Secretaria Nacional de Saneamento Ambiental, 2015.

BRASIL. Ministério das Cidades. Visão estratégica para o futuro do saneamento básico no Brasil panorama do saneamento básico no Brasil. Brasília: Ministério das Cidades/Secretaria Nacional de Saneamento Ambiental, 2011. v. 6.

NIPPON KOEI LAC. Plano de segurança hídrica das bacias hidrográficas estratégicas do Acaraú, Metropolitanas e da Sub Bacia do Salgado: relatório de coleta e diagnóstico das águas das bacias 
metropolitanas. Fortaleza: Nippon Koei Lac, 2017.

PREFEITURA MUNICIPAL DE PINDORETAMA - CEARÁ. Disponível em < http://pindoretama.ce.gov.br/>. Acesso em: 02 maio 2018.

SABESP - COMPANHIA DE SANEAMENTO BÁSICO DO ESTADO DE SÃO PAULO. Coleta de esgoto. Disponível em : http://site.sabesp.com.br/site/interna/Default.aspx?secaold=50. Acesso em: 25 maioci 2018.

SISTEMA NACIONAL DE INFORMAÇÕES SOBRE SANEAMENTO. Diagnóstico dos serviços de água e esgotos - 2015. Brasília: SNIS, 2017.

SISTEMA NACIONAL DE INFORMAÇÕES SOBRE SANEAMENTO. Diagnóstico dos serviços de água e esgotos - 2016. Brasília: SNIS, 2018.

SECRETARIA NACIONAL DE SANEAMENTO AMBIENTAL. Nota técnica SNSA N 492/2010 - Resumo 01/2011. Brasília: SNSA, 2011.

\section{Sobre os autores}

\section{Maria Jorgiana Ferreira Dantas}

Doutorado em Agronomia (Energia na Agricultura) pela Universidade Estadual Paulista Júlio de Mesquita Filho, Faculdade de Ciências Agronômicas (2013). Possui graduação em Recursos Hídricos/Saneamento Ambiental pela Faculdade de Tecnologia CENTEC-Cariri (2008), Mestrado em Engenharia Agrícola pela Universidade Federal do Ceará (2010), bolsista de doutorado sanduiche pela CAPES na Universidad de Valência/Espanha. Tem experiência na área de Saneamento Ambiental, Engenharia Agrícola, Sensoriamento Remoto e Expressão Gráfica com ênfase em Recursos Hídricos e Geoprocessamento Ambiental.

\section{Antônio Natanael Costa Sancho}

Mestrando do Programa de Pós - Graduação em Saneamento, Meio Ambiente e Recursos Hídricos (PPG-SMARH) da Universidade Federal de Minas Gerais (UFMG). Especialista em Engenharia de Segurança do Trabalho pela Faculdade Ateneu, Engenheiro Civil pela Universidade de Fortaleza (Unifor), Engenheiro Ambiental pela Universidade Federal do Ceará (UFC). Foi monitor da Coordenadoria de Formação e Aprendizagem Cooperativa (2010) e bolsista do Programa de Educação Tutorial - PET Engenharia Ambiental (2010 - 2014), no qual trabalhou em pesquisas na área de Saneamento Ambiental e na organização de eventos relacionados ao tema. É adulto voluntário da União dos Escoteiros do Brasil desde 2010. Trabalhou como analista ambiental na empresa Implement Gestão (2014-2015). Atuou como Engenheiro na Companhia de Água e Esgoto do Ceará - Cagece (2015 - 2018).

\section{José Jeová Ferreira Júnior}

Graduado em engenharia ambiental e sanitária pela Universidade de Fortaleza - Unifor. Tem experiência na área de Ciências Ambientais, com ênfase em Ciências Ambientais.

Recebido em: 12.07 .2018

Aceito em: 12.08.2019 